\title{
Genomic sequence analysis and characterization of Sneathia amnii sp. nov
}

Michael D Harwich $\mathrm{Jr}^{1 \dagger}$, Myrna G Serrano ${ }^{1,2+}$, Jennifer M Fettweis ${ }^{1}$, João MP Alves ${ }^{1,2}$, Mark A Reimers ${ }^{3}$, Vaginal Microbiome Consortium (additional members), Gregory A Buck ${ }^{1,2^{*}+}$, Kimberly K Jefferson ${ }^{1 *+}$

From The International Conference on Intelligent Biology and Medicine (ICIBM)

Nashville, TN, USA. 22-24 April 2012

\begin{abstract}
Background: Bacteria of the genus Sneathia are emerging as potential pathogens of the female reproductive tract. Species of Sneathia, which were formerly grouped with Leptotrichia, can be part of the normal microbiota of the genitourinary tracts of men and women, but they are also associated with a variety of clinical conditions including bacterial vaginosis, preeclampsia, preterm labor, spontaneous abortion, post-partum bacteremia and other invasive infections. Sneathia species also exhibit a significant correlation with sexually transmitted diseases and cervical cancer. Because Sneathia species are fastidious and rarely cultured successfully in vitro; and the genomes of members of the genus had until now not been characterized, very little is known about the physiology or the virulence of these organisms.

Results: Here, we describe a novel species, Sneathia amnii sp. nov, which closely resembles bacteria previously designated "Leptotrichia amnionii". As part of the Vaginal Human Microbiome Project at VCU, a vaginal isolate of S. amnii sp. nov. was identified, successfully cultured and bacteriologically cloned. The biochemical characteristics and virulence properties of the organism were examined in vitro, and the genome of the organism was sequenced, annotated and analyzed. The analysis revealed a reduced circular genome of $\sim 1.34 \mathrm{Mbp}$, containing $\sim 1,282$ protein-coding genes. Metabolic reconstruction of the bacterium reflected its biochemical phenotype, and several genes potentially associated with pathogenicity were identified.

Conclusions: Bacteria with complex growth requirements frequently remain poorly characterized and, as a consequence, their roles in health and disease are unclear. Elucidation of the physiology and identification of genes putatively involved in the metabolism and virulence of S. amnii may lead to a better understanding of the role of this potential pathogen in bacterial vaginosis, preterm birth, and other issues associated with vaginal and reproductive health.
\end{abstract}

\section{Background}

A recent study, based on phylogenetic and phenotypic analyses, showed that the organism previously named "Leptotrichia sanguinegens" should be reassigned to a separate genus. Thus, the genus Sneathia was described, and the species was formally named Sneathia sanguinegens [1]. Species of this genus are long, gram-negative,

\footnotetext{
* Correspondence: gabuck@vcu.edu; kkjefferson@vcu.edu

+ Contributed equally

'Department of Microbiology and Immunology, Virginia Commonwealth University School of Medicine, 1101 E. Marshall Street - PO Box 980678, Richmond, VA 23298-0678, USA

Full list of author information is available at the end of the article
}

non-motile rods that sometimes exhibit bulbous protrusions [2]. A novel bacterium that is closely related to S. sanguinegens was isolated from amniotic fluid and published as "Leptotrichia amnionii" [3]. The species was not validly named and no type strain was designated. Subsequently, 16S rDNA phylogenetic analysis showed that " $L$. amnionii" is better assigned to the genus Sneathia [4]. Herein, we describe a vaginal isolate that phenotypically and phylogenetically resembles this bacterium. Our genomic and phenotypic data clearly support the reclassification of this species to the genus 
Sneathia, and we propose the designation Sneathia amnii sp. nov. The type strain of S. amnii is Sn35.

Sneathia species have been associated with serious obstetric complications including spontaneous abortions and preterm labor $[3,5,6]$. While the uterine cavity and amniotic fluid are usually sterile, bacterial infection can occur and is frequently associated with preterm labor and preterm premature rupture of fetal membranes [7]. Sneathia is one of the most common genera detected in amniotic fluid, and its presence can lead to inflammation, histological chorioamnionitis, and/or amnionitis [8]. Two recent studies investigated the rates of bacterial invasion of the amniotic cavity. Amniotic fluid samples were analyzed for the presence of bacteria, and of samples from women with preeclampsia that were positive for bacteria, $50 \%$ contained Sneathia while in samples from women presenting with preterm labor that were positive for bacteria, 25\% contained Sneathia $[9,10]$. These findings suggest that Sneathia has the pathogenic capacity to invade the uterine cavity and the amniotic sac and thereby cause pregnancy complications. Sneathia has also been implicated in both infant and maternal post-partum bacteremia [11-13]. More recently, a case of septic arthritis in a healthy, non-pregnant woman was reported, demonstrating that this opportunistic pathogen has the potential to cause infections outside of the reproductive tract as well [11-13].

Sneathia has also been associated with bacterial vaginosis (BV), the most common vaginal disorder in women of reproductive age worldwide [14]. BV is thought to be a clinically significant disorder because it is associated with increased risk for preterm labor and increased rates of transmission of HIV and other sexually transmitted infections (STIs). BV is characterized by a decline in the number of healthy vaginal lactobacilli (long rods), and an increase in number of short rod-shaped and coccoid anaerobic bacteria. The overall bacterial load and species diversity are both drastically elevated in BV. The etiology of the disorder is poorly defined, complicating therapy, and BV tends to be recurrent [15]. Recent culture-independent techniques that comprehensively identify bacterial taxa associated with BV have been employed in an effort to better understand its etiology. Although these studies have revealed an association between BV and the presence of Sneathia sp., the role of these bacteria in the etiology and pathology of the disease remains undefined [16-18].

A recent study of the microbiome of the male urogenital tract found that men can also be colonized with Sneathia, and that there is a significant correlation between colonization with Sneathia and other sexually transmitted pathogens, suggesting that these bacteria can be sexually transmitted [19]. Another study investigated the rate of Sneathia colonization in female subjects with human papillomavirus (HPV), and while there was not a positive correlation between HPV and Sneathia, there was a significant correlation between colonization with S. amnii ("L. amnionii") and cervical cancer in HPVpositive subjects [20].

In summary, Sneathia appears to be a significant, emerging opportunistic pathogen that may play a significant role in vaginal and reproductive health. However, due to its fastidious nature, very little is known about the genus. Our analysis of mid-vaginal microbiome profiles from over 700 women who were recruited as part of the Vaginal Human Microbiome Project [21], revealed that Sneathia species, and especially $S$. amnii sp. nov., commonly inhabit the human vagina. In an effort to better define this microorganism, we cultured a vaginal isolate of Sneathia, analyzed its genetic virulence potential, and characterized its virulence properties in vitro. Herein, we describe $S$. amnii sp. nov. as a novel species that closely resembles isolates formerly designated as "L. amnionii," and designate the type strain as S. amnii Sn35. Furthermore, we sequenced and analyzed the genome of this strain, which represents the first genome for the Sneathia genus.

\section{Results and discussion}

\section{Sneathia species are a common component of the vaginal microbiota}

We collected mid-vaginal samples from 736 women visiting urban outpatient clinics in Virginia [21] for a variety of reasons (e.g., annual examination, vaginal discharge, STI screening, pregnancy, etc.). To identify the diversity of species present in these samples, we targeted the V1-V3 region of the $16 \mathrm{~S}$ ribosomal-RNA-encoding gene. We applied a deep-sequencing approach that generated an average of $\sim 30,000$ reads per sample (mean $=30,165$, median $=28,223$ ), and therefore were able to detect taxa present in low abundance. Sneathia species were found in $43.3 \%$ (319 of 736 ) of these samples using an abundance threshold of $0.1 \%$ of total reads (Figure 1a). Using a more stringent abundance threshold of $1 \%$ of total reads (i.e., approximately 300 reads for an average sample), we still detected Sneathia in $30.0 \%$ of samples. Notably, in three mid-vaginal samples, more than half of the total reads classified to Sneathia. Thus, organisms in the genus Sneathia are common members of the vaginal microbiome, and they are occasionally identified as the predominant taxa.

\section{S. amnii in mid-vaginal microbiome profiles}

The reference sequences of the V1-V3 regions of the $16 \mathrm{~S}$ rRNA genes of $S$. sanguinegens and $S$. amnii sp. nov. are only $91 \%$ identical, permitting clear separation of the $16 \mathrm{~S}$ rDNA metagenomic reads from these two species. Although we detected both $S$. sanguinegens and S. amnii in the mid-vaginal samples, the majority of Sneathia reads (76.3\%) classified to $S$. amnii (Figure 1b). Moreover, 

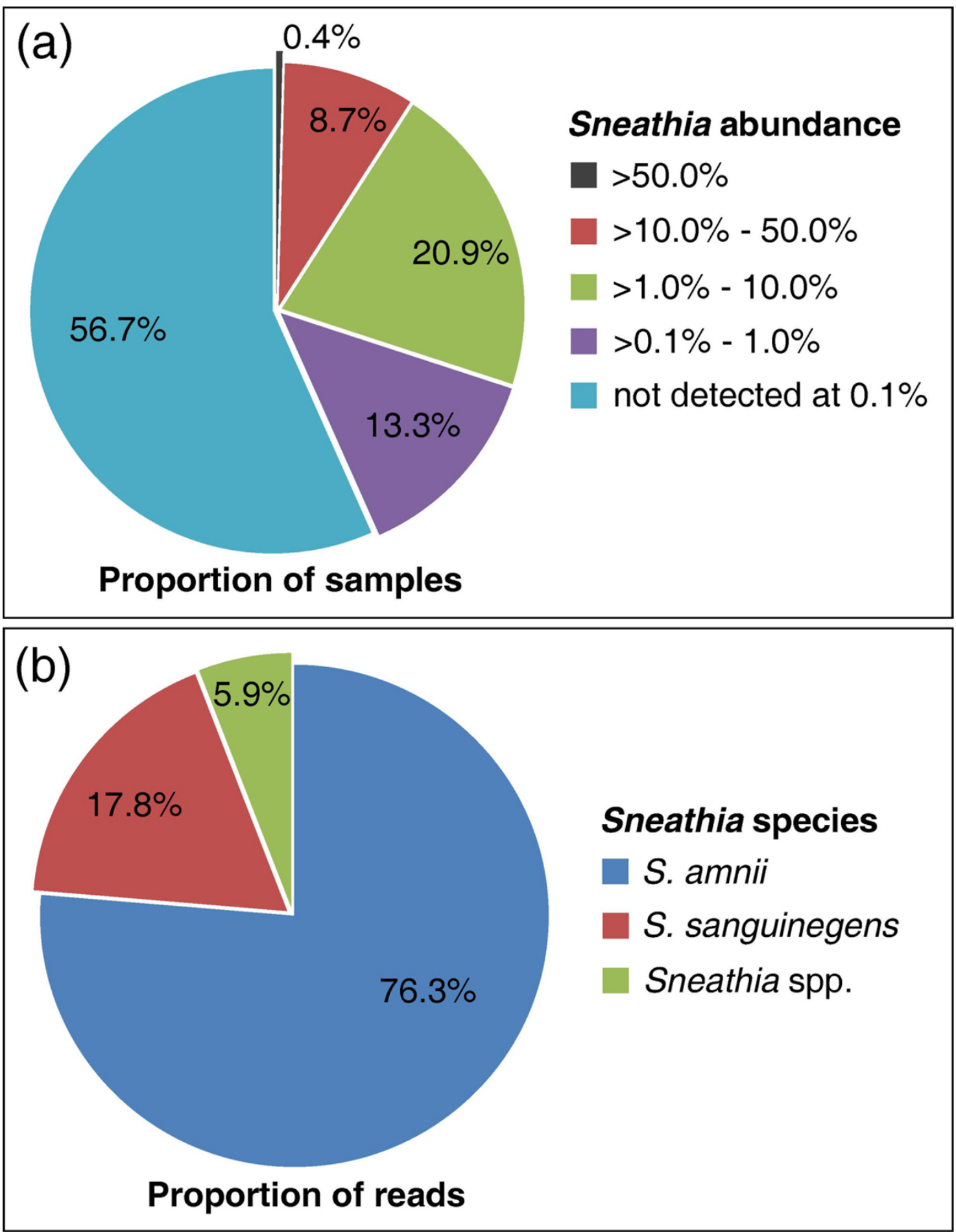

Figure 1 Prevalence of Sneathia species in mid-vaginal samples. (A) Relative abundance of Sneathia species in mid-vaginal samples. Sneathia was identified by 165 rDNA analysis in 319 of 736 mid-vaginal samples collected from volunteers recruited from outpatient clinics using a $0.1 \%$ abundance threshold; i.e., Sneathia was considered present if at least $0.1 \%$ of total $16 \mathrm{~S}$ rRNA reads classified to Sneathia. (B) Abundance of different species of Sneathia (S. sanguinegens, S. amnii, or non-speciated Sneathia) in mid-vaginal samples. The majority of Sneathia reads (76.3\%) identified in the mid-vaginal microbiome profiles classify to Sneathia amnii. 
both S. amnii and S. sanguinegens often co-occur in midvaginal samples. Using a $0.1 \%$ abundance threshold for presence, both $S$. amnii and S. sanguinegens were detected in $70.1 \%$ of mid-vaginal samples containing at least one of the two Sneathia species. However, approximately 6\% of all reads classified as Sneathia do not clearly classify to one of the two known Sneathia species. Our preliminary results indicate that there is likely a third, less-abundant vaginal Sneathia that has yet to be described. Reads classified to the novel putative Sneathia taxon were detected in $1.4 \%$ of samples using a $0.1 \%$ abundance threshold, representing $1.3 \%$ of all reads classifying to Sneathia at the genus level. The V1-V3 rDNA sequences from these bacteria are $\sim 91 \%$ and $~ 93 \%$ identical to corresponding rDNA sequences from $S$. amnii and $S$. sanguinegens, respectively, and these differences do not appear to be due to sequence errors or chimeras (data not shown). Thus, our results suggest that at least three related Sneathia types are found in vaginal samples. Herein, we focus on characterizing the $S$ amnii isolate, which we have successfully cultured and cloned, although we are continuing to attempt to culture and clone vaginal isolates of S. sanguinegens and the third, as yet unnamed, putative Sneathia.

\section{Phylogenetic analysis of the 16S rDNA of S. amnii}

To better define the role of $S$. amnii sp. nov. in vaginal health and disease, we isolated a clone from a mid-vaginal sample taken from an African American woman in her early 20's presenting with symptoms of preterm labor at 26 weeks of gestation. The $16 \mathrm{~S}$ rRNA gene of this isolate was sequenced in its entirety and aligned with the $16 \mathrm{~S}$ rDNAs from other members of Fusobacteriaceae family (Additional file 1) to assess their phylogenetic relationships (Figure 2). This alignment showed that the 16S rDNA of our isolate is $99.8 \%$ identical to the $16 \mathrm{~S}$ rDNA of the isolate first described as "L. amnionii" (accession number AY078425.1). This result, along with phenotypic characteristics, suggests that the Sneathia isolate described herein is very similar to the bacterium previously described by Shukla et al. (2002) [3]. Furthermore, the $16 \mathrm{~S}$ rDNA of our Sneathia isolate exhibited $94.7 \%$ overall sequence identity to $S$. sanguinegens (accession numbers L37789.1 and NR_025487.1), but only $84.4 \%$ overall sequence similarity to Leptotrichia buccalis (accession numbers L37788.1), the type species of the genus Leptotrichia. Phylogenetic analysis of the $16 \mathrm{~S}$ rDNA gene, are consistent with the classification of this bacterium to the genus Sneathia, as previously proposed by Eribe et al. [4] for the bacterium termed L. amnionii. Therefore, we propose $S$. amnii sp. nov. as the name for the species. Our analyses also confirm, as previously shown [1], the close relationship ( $\sim 88 \%$ across the rDNA, and similar relationships among other genes) between Sneathia and
Streptobacillus moniliformis, the causative agent of Rat bite fever [22].

\section{The genome of S. amnii sp. nov}

General features of the S. amnii genome are shown and compared to the genomes of the related bacteria S. moniliformis, L. buccalis, and Sebaldella termiditis in Table 1 . The genome was sequenced to 245 fold coverage using Roche 454 FLX Titanium technology, and this sequence assembled into one scaffold of $1,339,284$ bases (Figure 3). This initial assembly was interrupted by 27 sequence gaps ranging from $\sim 225$ to 4200 nucleotides. Gaps within the scaffold were filled by PCR ampliflication and capillary sequencing of the amplicons. Although mate pair sequencing permitted the assembly of the genome into a single circular scaffold, the final $(\sim 11)$ sequence gaps represent a very small fraction of the genome (a few hundred bases) and therefore are unlikely to impact our analyses.

The genome of Sneathia amnii is approximately 1.34 Mbp and has a GC content of $\sim 28 \%$. Thus, this organism exhibits the smallest of the Fusobacteriaceae family genomes sequenced to date. A representative from each of the most closely related genera; i.e., S. moniliformis (1.67 Mbp), L. buccalis (2.47 Mbp), and S. termiditis (4.49 $\mathrm{Mbp})$, was selected for genomic comparisons. The S. amnii genome exhibits 1,282 putative protein-coding genes, with an average gene length of 969 bp (323 amino acids), constituting $92 \%$ of the genome. Thus, the coding density of the genome is quite high. S. amnii intergenic regions have an average length of $80 \mathrm{bp}$, very similar to the 77 bp average intergenic size of $S$. moniliformis. The genomes of $L$. buccalis and $S$. termiditis have slightly larger intergenic regions, averaging 129 and 128 bp, respectively (Table 1). However, several studies have found no significant correlation between bacterial genome size and average intergenic region lengths [23]. We found that the differences in the gene composition account for the difference in the genome sizes of these related organisms. Although the genome of $S$. amnii is relatively small, its gene density (968 genes/Mbp) is higher than the average gene density of related members of the Fusobacteriaceae family, including S. moniliformis, L. buccalis and S. termiditis. This high gene density of $S$. amnii seems to be attributable to numerous overlapping genes. Our evidence also suggests that the $S$. amnii genome contains at least 110 overlapping genes. The compact genome of this organism supports a hypothesis that it is subject to selective pressures that attribute high cost to genome size and replication.

Of the 1,282 predicted genes of S. amnii, $852(\sim 66 \%)$ clustered into COG orthologous groups [24] and could be associated with a putative function. A comparison of COG functional groups for the selected Fusobacteriaceae genomes revealed a correlation of gene content with 


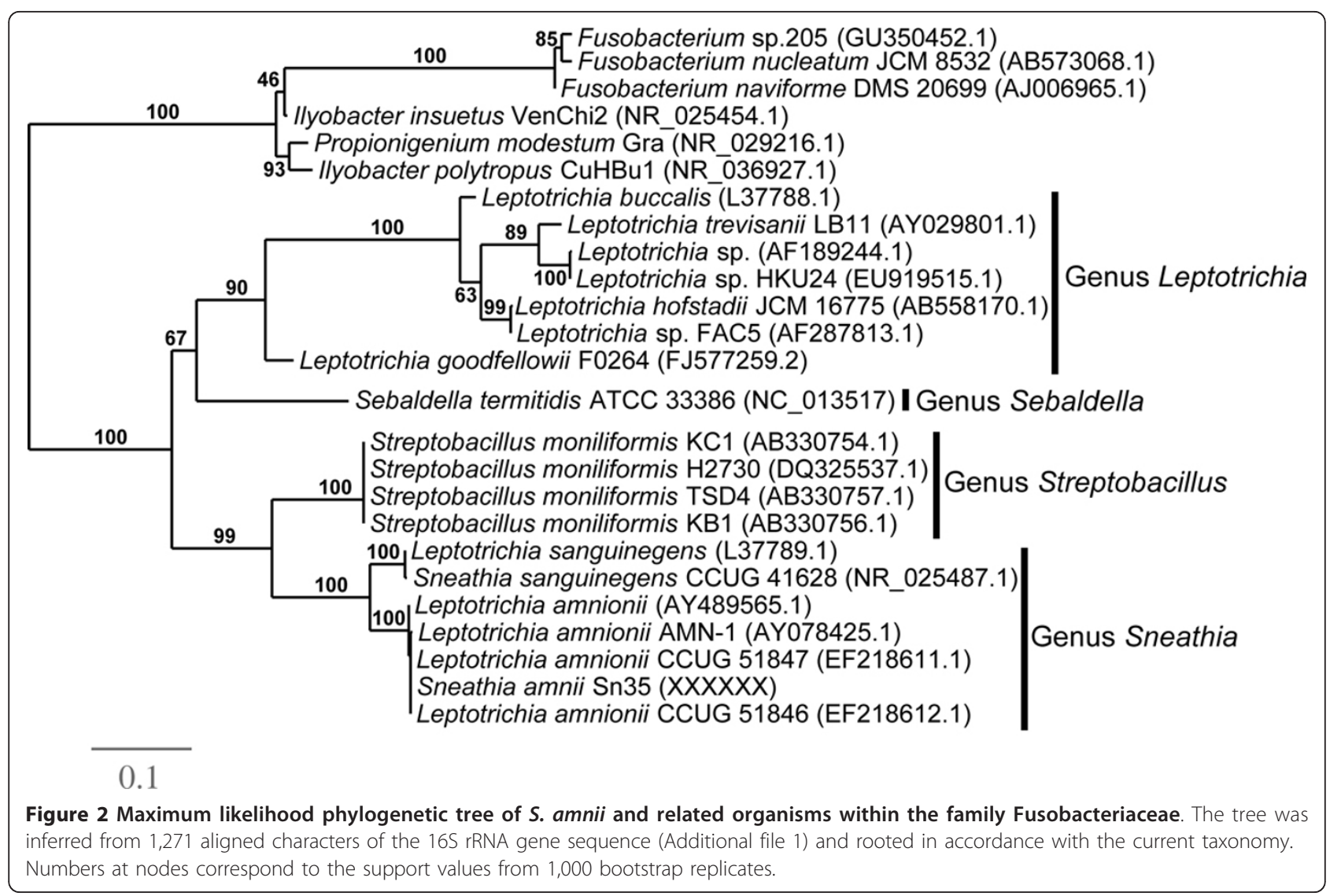

genome size (Figure 4). As observed previously [25], among the four taxa that we examined, gene contents for COG classes J, L, D and F are generally inversely correlated to genome size, whereas classes $\mathrm{K}, \mathrm{N}, \mathrm{T}$, and $\mathrm{Q}$ are generally positively correlated. COG groups J, L, D and F generally deal with DNA replication, cell cycle regulation and protein translation, whereas COG groups $\mathrm{K}, \mathrm{N}, \mathrm{T}$ and $\mathrm{Q}$ are associated with transcription, signal transduction, cell motility and the biochemistry of secondary metabolites (Figure 4, and Additional file 2). There is a

Table 1 General features of S. amnii genome and related organisms.

\begin{tabular}{|c|c|c|c|c|}
\hline & S. amnii & S. moniliformis & L. buccalis & S. termiditis \\
\hline Approximate Genome Size (bp) & $1,339,284$ & $1,673,280$ & $2,465,610$ & $4,486,650$ \\
\hline Total DNA Coding region (b) & $1,207,722$ & $1,556,870$ & $2,139,206$ & $3,918,335$ \\
\hline Average intergenic region (b) & 80 & 77 & 129 & 128 \\
\hline Average gene density (genes/Mbp) & 968 & 903 & 935 & 938 \\
\hline $\mathrm{G}+\mathrm{C}$ content $(\%)$ & 28.30 & 26.28 & 29.65 & 33.38 \\
\hline tRNA genes & 34 & 39 & 46 & 40 \\
\hline Predicted ORFS $^{1}$ & 1,282 & 1,511 & 2,306 & 4,210 \\
\hline Average ORF size in bp $(\mathrm{aa})^{2}$ & $942(314)$ & $1014(338)$ & $924(308)$ & $927(309)$ \\
\hline$\overline{\text { Genes assigned to } \mathrm{COGs}^{3}}$ & 1,042 & 1,111 & 1,731 & 2,229 \\
\hline Genes associated with a putative function ${ }^{4}$ & 852 & 907 & 1306 & 2164 \\
\hline Genes with signal peptides & 137 & 262 & 432 & 801 \\
\hline Genes with transmenbrane helices & 257 & 343 & 530 & 901 \\
\hline
\end{tabular}

Open reading frames predicted as described in the Materials and Methods;

${ }^{2}$ Average ORFs sizes shown herein were calculated using protein-coding sequences available at GeneBank: S. moniliformis (1434 protein sequences), L. buccalis (2220 protein sequences) and S. termiditis (4083 protein sequences);

${ }^{3}$ Clusters of orthologous groups as described in the Materials and Methods;

${ }^{4}$ Genes assigned to general functional prediction only (Category R) and function unknown (Category S) were not included. 


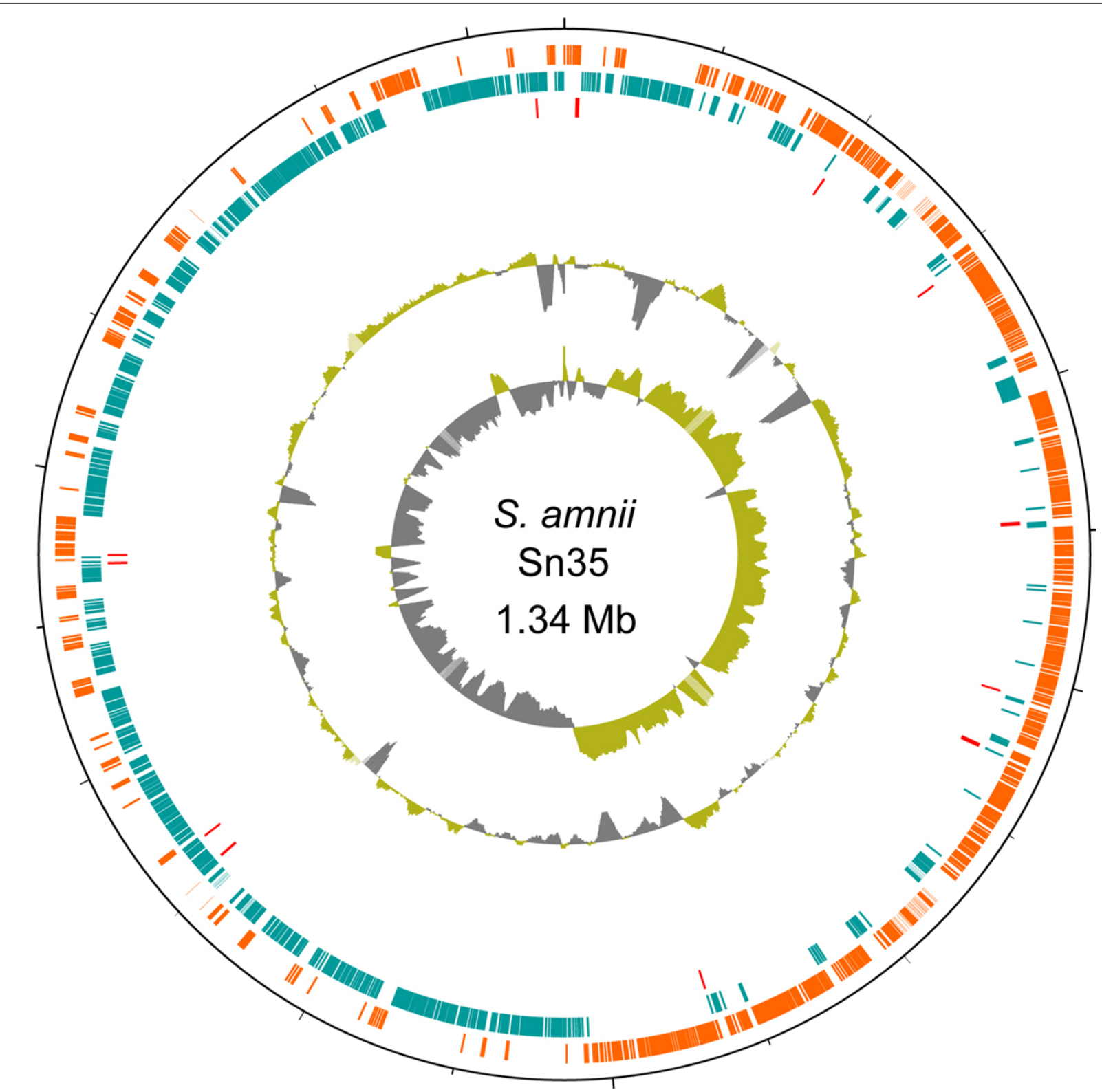

Figure 3 Genomic atlas of S. amnii Sn35. Coordinates are indicated starting from the predicted origin of replication at base 1. Circles represent the following (from the outer circle inward): 1) Coding regions are marked on the first two rings: orange color if encoded on the positive strand and teal color if encoded on the negative strand. 2) location of the tRNA. 3) GC content using a 10-kbp sliding window, green, positive GC skew; gray, negative GC skew. The innermost graph shows the GC skew, with sharp changes in skew occurring at the putative origin and terminus of replication. The atlas was constructed using DNAPlotter [58].

rationale for this in that as the genome size becomes compressed, functions of cell motility and signaling, which are dispensable or can be 'outsourced' to the host, are lost, while essential functions like DNA replication are maintained. As the total number of genes is reduced, the less important functions become a lower percentage of the remaining genes, and the more important functions become a higher percentage of the total. This trend was also apparent among genes not characterized in
COG, which is probably not surprisingly since these genes are likely to be involved in more specialized processes and may not be essential for growth and survival. Interestingly, whereas a positive correlation between genome size and COG class C (energy production and conversion) has previously been reported, we did not observe this correlation in our analysis of these four genomes (Figure 4). Thus, the general characteristics of this genome are fairly typical of a pathogen under pressure to 


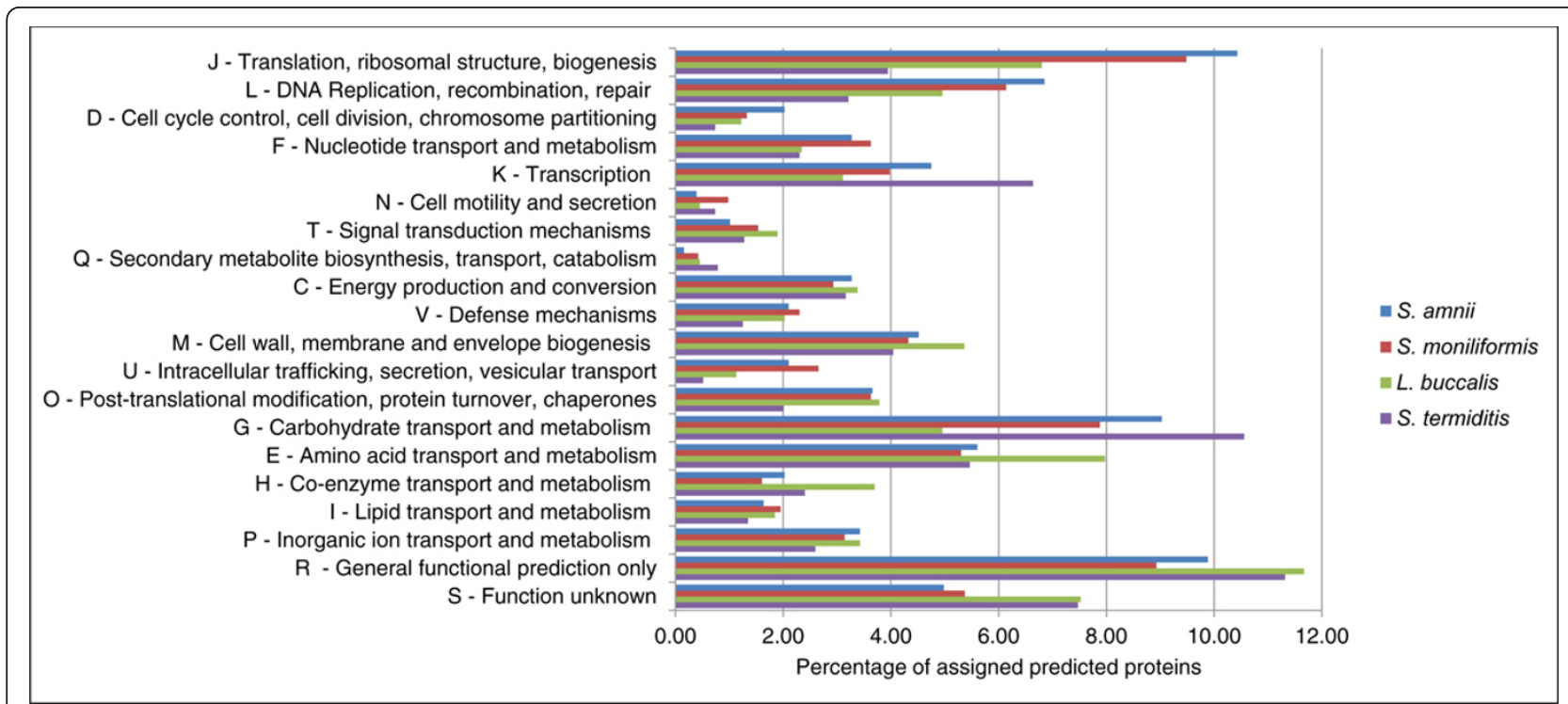

Figure 4 Comparison of the distribution of predicted proteins of S. amnii and related organisms. Predicted ORFs from S. amnii, S. moniliformis, L. buccalis and S. termiditis were classified into COG functional categories. The percent of genes belonging to each COG is represented for each species.

tailor its genetic capabilities to the bare essentials while taking maximum advantage of a close relationship with its mammalian host.

\section{Central metabolism}

Analysis of the metabolic potential of $S$. amnii provided insight into the biochemical reactions underlying the complex growth requirements of this fastidious organism. Our genome-wide metabolic reconstruction analyses suggested that $S$. amnii is able to metabolize a limited variety of carbohydrates, including glucose, maltose, glycogen and glucosamine. In contrast, Sneathia would be unable to ferment starch, mucin and mannose. The key enzymes; i.e. hexokinase, fructokinase, galactokinase, mannokinase and rhamnulokinase, needed for these conversions of the latter carbohydrates are missing in the genome of $S$. amnii. Fermentation assays confirmed that, as predicted, S. amnii ferments glycogen, maltose, and glucose, but not starch, galactose, mucin, mannose, sucrose or fructose. In addition, lactic acid was produced during fermentative metabolism as predicted by metabolic analyses. Since $S$. termiditis, L. buccalis and S. moniliformis, which clearly arose from a progenitor common to $S$. amnii, maintain these capabilities, these results support the hypothesis that $S$. amnii sp. nov. has lost many of the capabilities of its progenitors (Additional file 2).

Glycogen is produced by vaginal epithelial cells in women of reproductive age, and many known vaginal colonizers (e.g., the Lactobacillaceae) utilize this carbohydrate source. Therefore, it was not surprising that $S$. amnii, with its "reduced" metabolic capabilities, still effectively utilizes glycogen but can ferment only a few alternative carbon sources. Glycogen and glucose are the most abundant carbohydrate sources in the vagina, but fructose, mannose, glucosamine and starch are also present in lower amounts [26]. Maltose is an intermediate of glycogen metabolism and it is possible that $S$. amnii acquires this nutrient source from other bacteria that share the niche.

In silico analysis of the $S$. amnii genome revealed complete phosphotransferase systems (PTSs) for mannose, galactitol and cellobiose. Since we have empirically shown that S. amnii cannot metabolize mannose or galactose, the role(s) of these systems is unclear. In contrast, the majority of the sugar transporter PTS systems, including those for beta-glucosides, D-glucosamine, fructose, glucose, lactose, mannitol and sucrose, are incomplete. For these systems, genes for an EIIA component (phosphocarrier protein $\mathrm{HPr}$ ) are present, but no genes encoding putative permeases were identified. Thus, the functions of these incomplete PTS systems are currently unknown. Some studies suggest that, instead of carbohydrate transport, some of the enzymes in these systems may be involved in regulation of other biochemical pathways [27].

\section{Gene function \\ Energy metabolism}

Genes encoding enzymes of the non-oxidative branch of the pentose phosphate pathway (PPP), including the genes for transaldolase and transketolase, were identified 
in the genome. These enzymes link the PPP with glycolysis by catalyzing the conversion of dietary 5 carbon sugars into both 6 (fructose-6-phosphate) and 3 (glyceraldehyde-3-phosphate) carbon sugars, which can then be utilized by the pathways of glycolysis. It has been suggested that some human pathogens turn to gluconeogenesis to sustain growth when faced with limited sugar substrates [28]. However, our analyses suggest that $S$. amnii cannot use this strategy, since fructose bisphosphatase, an essential gene for gluconeogenesis, is apparently not present in its genome. Since the organism is anaerobic (see below), although moderately aerotolerant, it was not unexpected that enzymes for oxidative phosphorylation (e.g., fumarate reductase, succinate dehydrogenase) were absent from the genome. Additionally, the tricarboxylic acid (TCA) cycle of $S$. amnii appears to be absent, since only one of its required enzymes, dihydrolipoamide S-succinyltransferase, was detected in the 1.34 Mbp genome of the bacterium.

\section{Amino acid and nucleotide biosynthesis}

Loss of genes required for biosynthesis of amino acids is common among opportunistic pathogenic bacteria [29], and we found that $S$. amnii also lacks the enzymes required to synthesize most amino acids. In contrast, however, the enzymes needed to convert L-aspartate to fumarate, L-asparagine, and oxaloacetate appear to be present in the genome. In addition, many of the required enzymes that convert L-amino acids to D-amino acids were identified. As for genes required for amino acid biosynthesis, the genes required for de novo synthesis of purines and pyrimidines were not identified in the genome of S. amnii. However, several components of the salvage pathways for purine and pyrimidine biosynthesis were present. Thus, $S$. amnii apparently relies on the purine nucleotide salvage via adenosine and hypoxanthine. Adenosine is likely to be imported from host cells and converted into inosine by purine nucleoside phosphorylase. Hypoxanthine also appears to be derived from the host cell and then converted to inosine-5'-monophosphate (IMP) by hypoxanthine-guanine phosphoribosyltransferase. IMP serves as the precursor for both AMP and GMP, which are further converted to triphosphates. As part of the purine salvage process, the enzymes purinenucleoside phosphorylase and xanthine-guanine phosphoribosyltransferase are also encoded in this genome, and they are responsible for the conversion of the xanthosine to either xanthine or guanine to XMP or GMP, respectively. In addition, there are two alternative salvage pathways by which bacteria convert uridine to UMP. One is catalyzed by uracil phosphoribosyltransferase, the other requires the sequential enzymatic reactions of uridine phosphorylase and uridine kinase. Uridine kinase also converts cytidine to CMP. These key components of the pyrimidine salvage pathway are encoded in the $S$. amnii genome. Thus, despite the lack of many enzymes required for amino acid and nucleotide synthesis, $S$. amnii seems to be able to scavenge what it needs from its hosts.

\section{DNA repair and exchange}

A number of genes predicted to encode proteins involved in DNA modification and repair were also detected. Thus, we identified a putative DNA restriction-modification system. There are two genes encoding putative competence related proteins, but a complete system for genetic competence is apparently lacking, since the complex named RecBCD, composed of three different subunits called $\mathrm{RecB}, \mathrm{Rec}$, and RecD, was not found. Genes encoding apparent recombination proteins, including RecA, RecG, RecX, RecF, RecR, RuvABC, and viral RecT, were present. The genome contains a $u v r D$ homolog, but, like other pathogenic bacterial species with minimal genomes [30], other genes involved in UV-induced DNA repair, including $u v r A B C$, were not found and seem to be absent.

The $S$. amnii genome bears a complete temperate prophage genome in addition to several individual phagerelated genes dispersed throughout the genome. The prophage consists of a 20,259 kbp sequence containing both a lysogeny module, including putative integrase and repressor genes, and a replicative module, including genes encoding terminase, portal and tail proteins. Other phagerelated genes encoding integrases, a replisome organizer and a capsid are distributed throughout the genome. Two identical $1.2 \mathrm{kbp}$ insertion sequences are also present in the Sneathia genome. This insertion sequence has $99 \%$ identity to IS605, which was previously reported in the BV-associated Clostridiales species BVAB3, suggesting a possible cross genus transmission.

In brief, S. amnii exhibits the capacity for general DNA recombination and repair and while it does not appear to have the capacity for high-level natural competence, it has clearly acquired exogenous DNA, possibly through phage transduction and/or other mechanisms.

\section{Transport}

Few genes encoding known secretion systems were found; however, several genes predicted to encode homologs of the Type II protein secretion machinery (T2SS) were detected. Normally, components of T2SS are encoded within an operon located at a single genomic locus, although single genomes can contain multiple, discontiguous T2SS [31]. S. amnii contains genes homologous to both PulF/PilC and GspD proteins in a single locus. A second locus encodes a GspE homolog, hypothesized to be the ATPase that energizes Type II secretion, and a SecA homolog is located at a third locus. Taken together, these observations suggest that $S$. amnii has functional Sec and Type II secretion systems, although other protein secretion 
systems that were not identified by our analyses may also be present. In addition, there are many genes apparently related to small molecule transport, including $\sim 40 \mathrm{ABC}$ type transporter genes, $\sim 13$ genes involved in ion transport, and $\sim 7$ multidrug/lipid/protein pumps. Apparent homologs of the $\mathrm{F}_{1} \mathrm{~F}_{0}$ ATPase were also detected. In brief, $S$. amnii seems to be well equipped to obtain vitamins, cofactors and other nutrients from its environment.

\section{Growth requirements}

S. sanguinegens reportedly requires blood for growth [11]. In contrast, $S$. amnii did not require blood for growth, but its growth rate was enhanced by the addition of human serum (not shown). S. amnii grew well on chocolate agar. Colonies appeared after $48 \mathrm{~h}$, and by $72 \mathrm{~h}$ the colonies were flat, $\sim 1 \mathrm{~mm}$ in diameter, and crystalline. S. amnii did not grow on Brucella Sheep's blood agar but colonies on BHI agar containing 10\% fresh human blood were mucoid, raised, amorphous, $\sim 2 \mathrm{~mm}$ in diameter, and displayed alpha hemolytic activity. Consistent with our predictions from the genome analysis, S. amnii was catalase-negative and grew only under anaerobic conditions. However, it was able to tolerate transient exposure to air and was positive for superoxide dismutase activity. Interestingly, the genome did not contain an obvious gene encoding superoxide dismutase, and maximum identity to superoxide dismutase proteins, as detected using blastx, was $30 \%$.

\section{Morphology}

Scanning electron microscopy of S. amnii (Figure 5a) revealed variable morphology including long $(10+\mu \mathrm{m})$ gram-negative rods as well as short, amorphous rods and cocci. Similar short morphotypes have been reported for S. moniliformis [32], and other bacteria, and are referred to as "L forms". The L forms of S. moniliformis are reportedly deficient in cell walls and thought to be non-pathogenic. $S$. amnii L-forms were more common in older cultures, although actively growing cultures were predominated by the bacillary form. Tandem electron microscopy revealed that the long rods were actually chains of 1-2 $\mu \mathrm{m}$ long bacilli with rounded ends (Figure 5b). S. amnii did not appear to be motile, the genome does not contain genes predicted to encode pilin or flagellar proteins, and neither SEM nor TEM revealed structures that resemble pili or flagella.

\section{Antibiotic sensitivity}

We performed sensitivity assays for a number of antibiotics (Table 2). S. amnii displayed high resistance to nafcillin, as is common for other gram-negative organisms. The standard therapy for BV is metronidazole, but this therapy is suboptimal, and it is not known whether all BV-associated organisms are sensitive to this agent. Interestingly, S. amnii was more sensitive than Gardnerella vaginalis, another common BV-associated organism, to metronidazole. In contrast, S. amnii was more resistant than G. vaginalis to every other drug tested [33]. Gram-negative bacteria are generally resistant to the glycopeptide, vancomycin, because the large compound is unable to pass through the gram-negative outer membrane. In fact, vancomycin sensitivity is often used as an alternative test to gram staining and more than $99 \%$ of gram-negative clinical bacterial isolates, including Leptrotrichia species, are vancomycin resistant [34,35]. Thus, it was surprising that $S$. amnii was vancomycin-sensitive. This finding may suggest that the cell envelope of S. amnii differs from that of typical gram-negative bacteria, or it may be related to the large number of permeases and transporters predicted to be within the
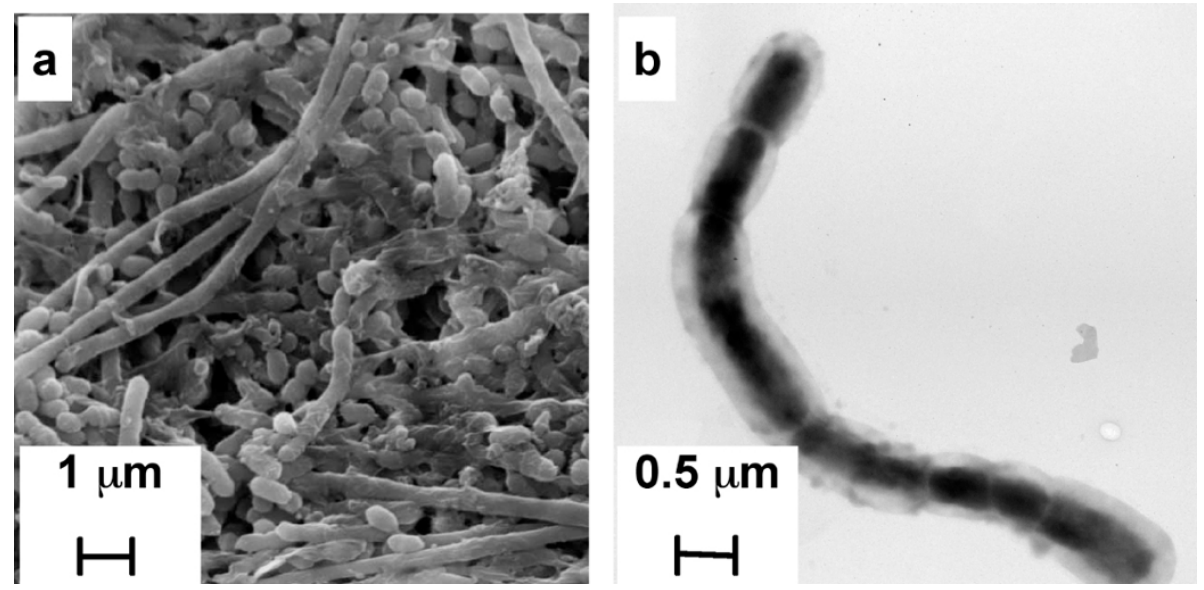

Figure 5 Electron Micrographs of S. amnii. S. amnii were fixed to either glass cover slips, or copper grids, and visualized by SEM (a) or TEM (b), respectively. 
Table 2 Sensitivity of S. amnii to antibiotics.

\begin{tabular}{cc}
\hline Antibiotic & MIC $(\boldsymbol{\mu g} / \mathbf{m l})$ \\
\hline Ampicillin & 9.8 \\
\hline Nafcillin & 1.25 \\
\hline Ciprofloxacin & 25 \\
\hline Nalidixic acid & 312 \\
\hline Chloramphenicol & 1.25 \\
\hline Minocycline & 0.97 \\
\hline Tetracycline & $>50$ \\
\hline Erythromycin & $>10$ \\
\hline Clindamycin & 5 \\
\hline Kanamycin & 6 \\
\hline Rifampin & 0.4 \\
\hline Metronidazole & 0.5 \\
\hline Vancomycin & 1.0
\end{tabular}

S. amnii envelope. Finally, S. amnii exhibited relatively high levels of resistance to antibiotics such as tetracycline (>50 $\mu \mathrm{g} / \mathrm{ml}$ ) and ciprofloxacin $(>25 \mu \mathrm{g} / \mathrm{ml})$. The genome encodes two apparent MATE efflux family homologs. Members of this family are frequently involved in drug export and single or multi-drug resistance and could be involved in resistance to these antimicrobial agents.

Although BV is associated with a greater than 2-fold increased risk for preterm birth, treatment with metronidazole during pregnancy does not reduce the risk for preterm birth [36]. BV involves the formation of a bacterial biofilm on the vaginal epithelium and the bacteria within these biofilms appear to be recalcitrant to metronidazole therapy, leading to a high rate of relapse [37]. Thus, even though S. amnii was sensitive to metronidazole, it may exhibit antibiotic tolerance if it occurs within the BV-associated biofilm. Therapeutic intervention strategies that target both the biofilm and the causative species may need to be developed in order to reduce the rate of BV-associated preterm birth.

\section{Hemolytic activity and cytotoxicity}

Consistent with the observation of alpha hemolysis on blood agar, S. amnii exhibited weak hemolytic activity. $S$. amnii induced the release of $\sim 9 \%$ of the hemoglobin from human red blood cells while an E. coli strain without hemolytic activity lead to the release of less than $0.5 \%$. The genome encodes a putative hemolysin of approximately $28 \mathrm{kDa}$ that could be responsible for the hemolytic activity. It also encodes a large protein $(161 \mathrm{kDa})$ with homology to both hemagglutinins and hemolysins. However, hemagglutination of human red blood cells was not observed. S. amnii was cytotoxic to ME-180 human cervical cancer cells. Thus, after 2 hours of exposure, the cervical epithelial cells exhibited rounding and other cytopathic changes associated with cytotoxicity (Figure 6a, b), suggesting the existence of a toxin that causes damage to these cells. Although a cytotoxin was not annotated in the genome, one of the hemolysins discussed above could be responsible for this activity.

\section{Adherence to cervical epithelial cancer cells}

S. amnii adhered to ME-180 human cervical cancer cells (Figure 6c). The image also reveals apparent perforations in the epithelial cells near the site of bacterial adherence that were not present in untreated cells (not shown), suggesting that the bacteria may be causing local membrane damage. The duration of the adherence was minimized to prevent major cytopathogenic changes; however, it is likely that cytotoxic effects were starting to manifest. The $S$. amnii genome contains only one apparent adhesin homolog, but three apparent homologs of the Hia family cell surface protein and a number of YadA domain-containing proteins are present $[38,39]$. The Hia and YadA families are autotransporters often implicated in adherence to host tissues and cells. There is also a gene encoding a putative fibronectin-binding protein, which could play a role in adherence to host tissues.

\section{Other genetic components with potential roles in virulence}

We did not detect any putative quorum-sensing systems. However, only a few systems including the LuxS system are highly conserved and it is possible if not likely that a quorum-sensing system would be difficult to detect. A putative toxin-antitoxin cassette was found. These cassettes can play a role in the stabilization of foreign DNA, such as plasmids [40]. They have also been shown to contribute to stress resistance and the persister phenotype [41]. Sneathia has been isolated from amniotic fluid and therefore presumably has the capacity to invade the uterine cavity and traverse the fetal membranes.

Very little is known about virulence factors that promote uterine and intra-amniotic invasion although it has been speculated that enzymes including sialidase that hydrolyze sialic acid residues or enzymes that degrade sialylated proteins plays a role in traversal of the cervical mucus [42]. Sneathia encoded a protein with $63 \%$ identity and $77 \%$ similarity to a O-sialoglycoprotein endopeptidase that could be involved in the degradation of sialylated proteins. Evidence suggests that Listeria crosses the gestational membranes through villous syncytiotrophoblasts, and that the invasin, internalin is required for this process [43]. Sneathia encoded a number of potential invasins. The YadA-like surface protein mentioned as a putative adhesin has also been implicated in invasion. It also encodes a protein with $22 \%$ identity and $37 \%$ similarity to internalin $\mathrm{F}$ from Clostridium perfringens.

Clustered regularly interspaced short palindromic repeats (CRISPR) are hypervariable sequences that are 


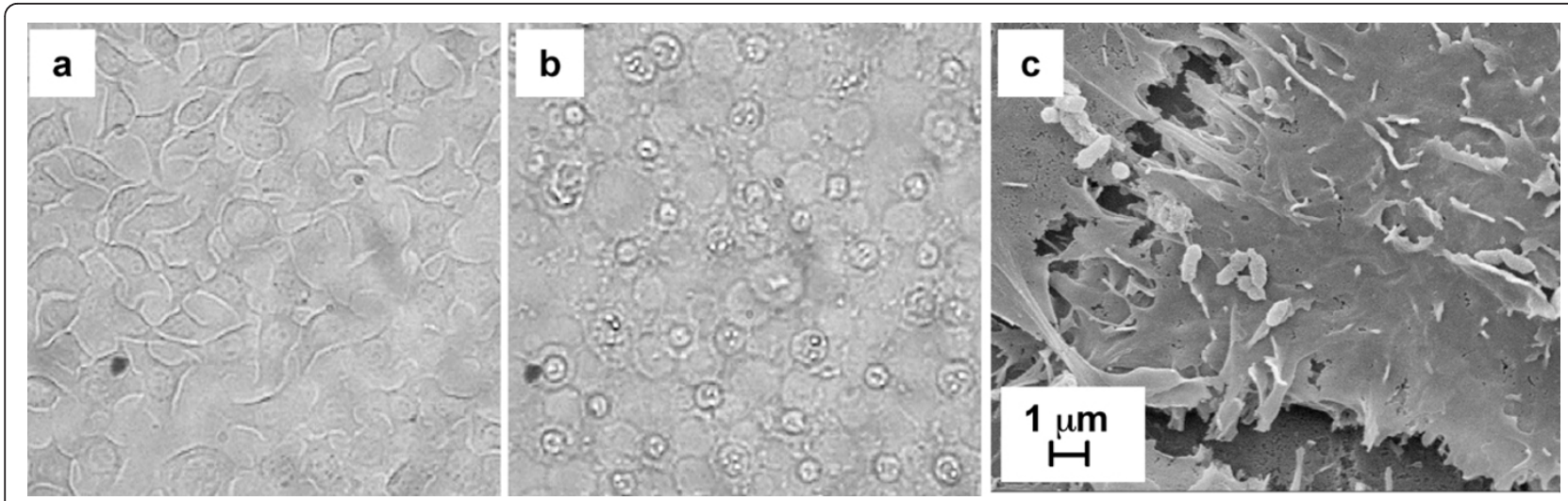

Figure 6 S. amnii was cytotoxic and adhered to Me180 cells. To assess cytotoxicity, bacteria were added to Me180 monolayers and monitored by light microscopy during the incubation for phenotypic alterations. In stark contrast to monolayers treated with PBS alone as a control (a), monolayers exposed to S. amnii rapidly induced cell rounding and loss of adherence (b). To determine whether or not S. amnii adhered, bacteria were added to Me180 monolayers grown on glass coverslips. Following incubation, the glass coverslips were washed extensively in PBS, stained, and analyzed by SEM (c).

widely distributed in bacteria and archaea and play critical roles in the adaptation and persistence of a microbial host in a particular ecosystem by providing acquired resistance against viruses [44]. Using CRISPFinder [45] we identified one CRISPR locus with nine 36 bp direct repeats (DR) located adjacent to the putative cas gene. These finding suggest the presence of a functional CRISPR system in S. amnii.

\section{Conclusions}

Sneathia is one of the most frequently detected organisms from amniotic fluid in cases of preterm labor, suggesting an important role in obstetric health. We detect Sneathia species in over $40 \%$ of mid-vaginal samples in our ongoing study. The fastidious nature of Sneathia makes cultivation somewhat difficult, and consequently, very little is known about its biology or its pathogenic potential. The first genomic sequence of an organism in the genus Sneathia provides a starting point for the detailed study of these organisms and their role in obstetric and gynecologic health. The genome is small, approximately $1.34 \mathrm{Mbp}$, and highly reduced, which may be the basis of its fastidious nature. Metabolic reconstructions of the genome revealed capacities that largely reflect the known metabolic, energy, and anaerobic phenotypes of the bacterium. We did observe an increased growth phenotype in the presence of human serum, which was not reproducible using fetal bovine serum (data not shown), reaffirming the highly specialized nature of this organism for the human niche. Our results indicate that $S$. amnii is able to adhere to, and has high cytotoxic potential for, cervical epithelial cells. Analysis of the genome sequence revealed a hemolysin, which could exert this cytotoxic activity. While $S$. amnii was sensitive to metronidazole in our assay, BV-associated biofilms may confer antibiotic tolerance to species that appear sensitive in vitro and have been shown to be involved in the high rate of relapse. In summary, the genome of this emerging pathogen reflects its phenotype and begins to shed light on the reveal its pathogenic potential and likely role in the gynecologic and obstetric complications associated with S. amnii.

\section{Description of Sneathia amnii sp.nov}

>Sneathia amnii (am'ni.i. Gr. n. amnion, inner membrane surrounding the fetus; N.L. gen. n. amnii, of the amnion, pertaining to the amniotic fluid from which the organism was first isolated) consists of long gram-negative rods as well as short, amorphous rods and cocci. Closer examination suggests that the long rods are chains of short rodlike bacteria. Colonies on blood agar plates after 72 hours were flat, $\sim 1 \mathrm{~mm}$ in diameter, and crystalline. Colonies on BHI agar containing $10 \%$ fresh human blood were $\sim 2$ $\mathrm{mm}$ in diameter and displayed alpha hemolytic activity. Cells were catalase-negative, aerotolerant, and optimal growth occurred under anaerobic conditions. Fermentation of glycogen, maltose, and glucose were demonstrated. Lactic acid was produced during fermentative metabolism. Strains have been isolated from human clinical specimens (mid-vaginal wall, amniotic fluid). The type strain of S. amnii, Sn35, has a \%G+C of $\sim 28 \%$ and a genome of $\sim 1.34 \mathrm{Mbp}$.

\section{Methods}

\section{Subject recruitment}

We enrolled adult women from outpatient women's health clinics in Virginia as part of the Vaginal Human Microbiome Project [21]. Incarcerated women and women who were not scheduled for a vaginal examination were excluded from the study. Enrollment occurred between August 2009 and March 2011. Written consent 
was obtained from all study participants and the institutional review boards at Virginia Commonwealth University and the Virginia Department of Health approved the study. Clinicians obtained swab samples from the midvaginal wall during a speculum examination.

\section{Metagenomic 16S rRNA gene identification of Sneathia in mid-vaginal samples}

DNA was extracted within four hours of collection using the MoBio PowerSoil DNA processing protocol. The V1-V3 region of the 16S rRNA gene was PCR-amplified with bar-coded primers and sequenced on a Roche 454 FLX Titanium Genome Sequencer as described in [21].

\section{Isolation and growth conditions}

Bacteria from a swab sample taken from the mid-vaginal wall of a female volunteer were cultured on chocolate agar at $37^{\circ} \mathrm{C}$ for $72 \mathrm{~h}$ using the AnaeroPack system (Mitsubishi Gas Chemical Co, Tokyo, Japan). Single colonies were isolated and 'colony' PCR was performed using $16 \mathrm{~S}$ rDNA-specific primers UnivFwd (AGAGTTTGATCCTG GCTCAG) and UnivRev (5'- GGACTACCAGGGTATCTAAT -3') [46] and PCR Supermix HiFi (Invitrogen). PCR conditions were $94^{\circ} \mathrm{C} 2$ min followed by 35 cycles of $94^{\circ} \mathrm{C} 30 \mathrm{~s}, 51^{\circ} \mathrm{C} 30 \mathrm{~s}$, and $72^{\circ} \mathrm{C} 30 \mathrm{~s}$. PCR products were sequenced and species identification was based on identity with $16 \mathrm{~S}$ rDNA sequences in the NCBI database. Following initial isolation, $S$. amnii was grown on chocolate agar or in Brain Heart Infusion (BHI) broth (EMD, Gibbstown, NJ) supplemented with $1 \%$ yeast extract, $2 \%$ gelatin, $0.1 \%$ starch, $0.1 \%$ glucose, and $5 \%$ human serum (sBHI) at $37^{\circ} \mathrm{C}$ under anaerobic conditions. To analyze carbohydrate fermentation, $5 \%$ human serum, $0.002 \%$ phenol red, and $1 \%$ sugar (glucose, starch, maltose, galactose, glycogen, mucin, mannose, sucrose, or fructose) were added to chemically defined vaginal fluid medium (described in [47]), $200 \mu \mathrm{L}$ of the medium was aliquoted into 96 well plates, and inoculated with $S$. amnii. The plates were incubated anaerobically and inspected visually at $24 \mathrm{~h}$ and $48 \mathrm{~h}$ for signs of growth (turbidity) and acid production (change in media color from red to yellow). Lactic acid was measured using the Lactate Assay Kit (Biovision, Mountain View, Ca) according to manufacturer's instructions.

\section{Superoxide dismutase activity}

Approximately $2 \times 10^{9}$ bacteria were resuspended in $500 \mu \mathrm{L}$ Tris EDTA buffer (TE) and lysed with $500 \mu \mathrm{L}$ of $1 \mu \mathrm{m}$ glass beads twice at power 6.5 for $30 \mathrm{~s}$, in a Fastprep cell disrupter (Thermo). Protein concentration was determined by measuring $\mathrm{A}_{260} \mathrm{~nm}$ on a Nanodrop ${ }^{\mathrm{TM}}$ spectrophotmeter. Superoxide Dismutase activity was measured using the Superoxide Dismutase Assay Kit (Cayman Chemical Company, Ann Arbor, MI). Briefly, $10 \mu \mathrm{L}$ of lysate were added to $200 \mu \mathrm{L}$ of the diluted radical detector, the reaction was initiated by addition of $20 \mu \mathrm{L}$ diluted xanthine oxidase and incubated at room temperature for 20 min with gentle mixing. Units of activity were calculated by comparing the $\mathrm{A}_{450 \mathrm{~nm}}$ to the standard provided by the manufacturer.

\section{DNA isolation and sequencing}

S. amnii was grown in $20 \mathrm{~mL}$ sBHI overnight. The cells were collected by centrifugation, and DNA was isolated using the Genomic-tip 500/G (Qiagen) according to manufacturer's instructions. Genome sequencing of S. amnii was performed with a combined strategy using whole genome shotgun and 8-kilobase pair $(\mathrm{kbp})$ paired-end reads. For the shotgun library, fifty nanograms of DNA were used in a tagmentation reaction with a Nextera ${ }^{\mathrm{TM}}$ DNA Sample Prep Kit (Roche Titanium-compatible, Epicentre Biotechnologies) following the manufacturer's protocol. For the paired end library, genomic DNA was fragmented into 8-kbp fragments using our HydroShear ${ }^{\mathrm{TM}}$ DNA Shearing Device (GeneMachines, Inc.). Further paired-end library preparation was performed according to the manufacturer's protocols (Roche). The genomic libraries of S. amnii were sequenced on the Roche 454 FLX Titanium system in the Nucleic Acids Research Facilities at VCU. A total of 583,691 shotgun reads and 287,309 paired-end reads yielded a $\sim 247$-fold coverage of the genome. The reads were assembled using Newbler ${ }^{\mathrm{TM}}$ version 2.0.00.20 software (Roche) using default parameters. The final assembly generated a single circular scaffold containing the entire genome. Closure of physical gaps was performed by PCR amplification using primers targeted to contigs flanking the gaps, followed by fluorescent chain termination sequence analysis on AB3730 or AB3130 capillary sequencers (Applied Biosystems).

\section{Gene calling and analysis}

Genes were called using Glimmer 3 [48] using default parameters. Transfer RNA genes were predicted using tRNAscan-SE 1.23 [49] and ribosomal RNA genes were found by similarity search. Sequences were initially annotated by comparison with currently annotated bacterial sequences present in NCBI's NR protein database. Metabolic reconstruction and Gene Ontology classification assignments were performed using ASGARD software [50] in conjunction with the UniRef100 database [51]. Other annotation features were predicted as follows: transmembrane domains by TMHMM 2.0c [52]; signal peptides by SignalP 3.0b [53]; COG similarities and Pfam domain composition by rpsblast [24]

\section{Phylogenetic analysis}

The 16S rDNA sequences of S. amnii and 31 related organisms from Fusobacteriaceae family were aligned using the ClustalW program [54] and the alignments were 
corrected by visual inspection. Phylogenetic analysis was performed from 1,271 aligned characters of the 16S rRNA sequences under the maximum likelihood criterion [55]. Maximum likelihood trees were inferred using PhyML 3.0 program $[56,57]$ using the HKY85 model, gamma shape parameter and proportion of invariable sites. Model parameters were estimated in PhyML over the duration of the tree search. The numbers at the nodes are the result of a PhyML bootstrap analysis.

\section{Antibiotic sensitivity assay}

Antibiotics were serially diluted 2-fold in $200 \mu \mathrm{L}$ sBHI in mictotiter wells and $5 \mu \mathrm{L}$ of a $48 \mathrm{~h}$ bacterial culture was added to each well. The microtiter plates were incubated anaerobically for $48 \mathrm{~h}$ and the lowest concentrations of antibiotics that prevented visible bacterial growth were recorded.

\section{Electron microscopy}

For tandem electron microscopy, bacteria grown in sBHI were collected by centrifugation, washed in sterile deionized water, spotted onto formvar-coated 200-mesh copper grids (Electron Microscopy Sciences, Hatfield, PA), stained with $2 \%$ phosphotungstic acid, and analyzed using a Jeol JEM-1230 transmission electron microscope equipped with a Gatan UltraScan 4000SP $4 \mathrm{~K} \times 4 \mathrm{~K}$ CCD camera. For scanning electron microscopy, washed bacteria were fixed in $2 \%$ gluteraldehyde. To visualize adherence to cervical epithelial cells, washed bacteria were added to ME-180 human cervical cancer cell monolayers grown on poly-lysine-coated glass coverslips, incubated for $5 \mathrm{~min}$, and the monolayers were washed 3 times with $1 \times$ PBS to remove non-adherent bacteria. The monolayers were fixed in $2 \%$ gluteraldehyde. All samples were then rinsed, fixed in $1 \%$ osmium tetraoxide, rinsed, and then dehydrated with washes of increasing concentrations of ethanol followed by hexamethadisilizane (HMDS), mounted, and coated with gold using an EMS 550 Sputter Coater (Electron Microscopy Sciences, Hatfield, PA) just prior to viewing. Samples were analyzed using a Zeiss EVO50XVP Scanning Electron Microscope (Carl Zeiss SMT, Inc., Peabody, MA).

\section{Hemolysis and hemagglutination}

Fresh human blood collected with EDTA as an anticoagulant was centrifuged at $500 \times \mathrm{g}$ for $10 \mathrm{~min}$. The serum was removed, the red blood cells (RBC) were washed once in 10 volumes of phosphate buffered saline (PBS), and resuspended in 10 volumes of fresh PBS. $100 \mu \mathrm{L}$ of the RBC were added to $0.5 \mathrm{~mL}$ microfuge tubes. Approximately $1 \times$ $10^{6}$ bacteria from $24 \mathrm{~h}$ liquid cultures of S. amnii or E. coli (negative control) were washed with PBS and added to the RBC-containing microfuge tubes. PBS was used as a negative control. The tubes were incubated, stationary, for
$30 \mathrm{~min}$ at $37^{\circ} \mathrm{C}$ and observed visually for lattice formation (hemagglutination). The tubes were centrifuged at $500 \times \mathrm{g}$ for $10 \mathrm{~min}$, the supernatant was collected, and the $\mathrm{A}_{450}$ was determined as a measure of hemoglobin release. RBCs lysed in pure water were used as a positive control for $100 \%$ hemolysis. Bacteria-induced hemolysis was calculated as the percentage relative to the positive control as $100 \%\left[\left(\mathrm{~A}_{450}\right.\right.$ Bacteria $\left.-\mathrm{A}_{450} \mathrm{PBS}\right) / \mathrm{A}_{450}$ water $]$.

\section{Cytotoxicity}

S. amnii was cultured in sBHI, collected by centrifugation, and resuspended in PBS to an $\mathrm{OD}_{600}=1.0$. Two-fold serial dilutions were made. ME-180 human cervical cancer cells were cultured at $37^{\circ} \mathrm{C}$ in $5 \% \mathrm{CO}_{2}$ in McCoy's $5 \mathrm{~A}$ medium (Quality Biologic, Gaithersburg, MD) supplemented with $10 \%$ fetal bovine serum and $1 \mathrm{IU} \mathrm{mL}^{-1}$ penicillin/streptomycin (MediaTech, Manassass, VA) in 96 well plates. Once the cells reached $\sim 90 \%$ confluence, the media was replaced with $100 \mu \mathrm{L}$ PBS, and $100 \mu \mathrm{L}$ of each bacterial dilution was added. The monolayers were monitored every hour by light microscopy for cytopathogenic changes, such as cell rounding, loss of adhesion, and disruption of the monolayer. Photos were taken using an Olympus CK2 light microscope at magnifications of 100x and 400x.

\section{Authors' details}

All authors are members of the Vaginal Microbiome Consortium. Additional members of the Vaginal Microbiome Consortium who contributed to this study are listed in alphabetical order: James P. Brooks, Christopher J. Friedline, Philippe H. Girerd, Stephanie L. Hendricks, Vladimir Lee, Melissa A. Prestosa, Federico A. Puma, Maria C. Rivera, Nihar U. Sheth, Jerome F. Strauss III, and Logan J. Voegtly.

\section{Additional material}

\begin{abstract}
Additional file 1: Supplementary figure S1 - Multiple sequence alignment of $16 \mathrm{~S}$ rDNA from S. amnii and related organisms. Alignment of $16 \mathrm{~S}$ rDNA sequences of $\mathrm{S}$. amnii and representative strains belonging to seven representants of the Fusobacteriaceae family: Sneathia, Streptobacillus, Leptotrichia, Sebaldella, Propionigenium, Ilyobacter, and Fusobacterium.

Additional file 2: Supplementary table 1 - Fraction of genes associated with specific COG functional groups in each species.

Additional file 3: Supplementary table 2 - In silico reconstruction of the metabolic pathways of S. amnii, S. moniliformis, L. buccalis and S. termiditis.
\end{abstract}

\section{Acknowledgements}

This work was supported by Grant 4UH3AI083263, The Vaginal Microbiome: Disease, Genetics and the Environment, from the National Institutes of Health and in part by a Virginia Commonwealth University President's Research Initiative Fund. Sequencing was performed in the High Throughput Genomics Core of the Nucleic Acids Research Facilities at VCU, supported in part by funding from NIH_NCI 2P30 CA16059. Sequence analysis was 
performed with infrastructure and support from the Bioinformatics Computational Core Laboratory and the Center for High Performance Computing at VCU. Microscopy was performed at the VCU - Dept. of Neurobiology \& Anatomy Microscopy Facility, supported, in part, with funding from NIH-NINDS Center core grant (5P30NS047463).

This article has been published as part of BMC Genomics Volume 13 Supplement 8, 2012: Proceedings of The International Conference on Intelligent Biology and Medicine (ICIBM): Genomics. The full contents of the supplement are available online at http://www.biomedcentral.com/ bmcgenomics/supplements/13/S8.

\section{Author details}

'Department of Microbiology and Immunology, Virginia Commonwealth University School of Medicine, 1101 E. Marshall Street - PO Box 980678, Richmond, VA 23298-0678, USA. ${ }^{2}$ Center for the Study of Biological Complexity, Virginia Commonwealth University, 1015 Floyd Avenue, PO Box 842030, Richmond, VA 23284-2030, USA. ${ }^{3}$ Department of Biostatistics, Virginia Commonwealth University School of Medicine, 830 East Main Street - PO Box 980032, Richmond, VA 23298-0032, USA.

\section{Authors' contributions}

MDH isolated S. amnii, performed biochemical, cytotoxicity, adhesion, and antibiotic sensitivity assays, performed electron microscopic analysis and wrote the manuscript.

MGS performed sequence analysis, assembly, annotation, metabolic reconstruction, phylogenetic analysis, and wrote the manuscript. JMF coordinates the Vaginal Human Microbiome Project, speciated Sneathia in the microbiome dataset, analyzed Sneathia carriage rates, contributed to phylogenetic analysis and interpretation of metabolic reconstruction, and wrote the manuscript.

JMA contributed to sequence analysis, assisted with the metabolic reconstructions, and edited the manuscript.

MAR assisted in identifying the importance of Sneathia in the vaginal microbiome.

Vaginal Microbiome Consortium members contributed to the design and execution of the study, provided creative feedback, and added to the collective interpretation of the relevance of the results to vaginal health. GAB conceived the research plan, oversaw the project, directed the analysis pipelines, set research priorities, provided creative interpretation of the results, and assisted in the content and writing of the manuscript. KKJ designed the research, supervised the microbiological and biochemical analyses, interpreted the data, and assisted in the content and writing of the manuscript.

All authors have read and approved the final version of the manuscript.

\section{Competing interests}

The authors declare that they have no competing interests.

Published: 17 December 2012

\section{References}

1. Collins MD, Hoyles L, Tornqvist E, von Essen R, Falsen E: Characterization of some strains from human clinical sources which resemble "Leptotrichia sanguinegens": description of Sneathia sanguinegens sp. nov., gen. nov. Syst Appl Microbiol 2001, 24(3):358-361.

2. Goto M, Hitomi S, Ishii T: Bacterial arthritis caused by Leptotrichia amnionii. J Clin Microbiol 2007, 45(6):2082-2083.

3. Shukla SK, Meier PR, Mitchell PD, Frank DN, Reed KD: Leptotrichia amnionii sp. nov., a novel bacterium isolated from the amniotic fluid of a woman after intrauterine fetal demise. J Clin Microbiol 2002, 40(9):3346-3349.

4. Eribe ER, Paster BJ, Caugant DA, Dewhirst FE, Stromberg VK, Lacy GH, Olsen I: Genetic diversity of Leptotrichia and description of Leptotrichia goodfellowii sp. nov., Leptotrichia hofstadii sp. nov., Leptotrichia shahii sp. nov. and Leptotrichia wadei sp. nov. Int J Syst Evol Microbiol 2004, 54(Pt 2):583-592.

5. Boennelycke M, Christensen JJ, Arpi M, Krause S: Leptotrichia amnionii found in septic abortion in Denmark. Scand J Infect Dis 2007, 39(4):382-383.

6. Thilesen CM, Nicolaidis M, Lokebo JE, Falsen E, Jorde AT, Muller F: Leptotrichia amnionii, an emerging pathogen of the female urogenital tract. J Clin Microbiol 2007, 45(7):2344-2347.

7. Goldenberg RL, Culhane JF: Infection as a cause of preterm birth. Clin Perinatol 2003, 30(4):677-700.
8. Han YW, Shen T, Chung P, Buhimschi IA, Buhimschi CS: Uncultivated bacteria as etiologic agents of intra-amniotic inflammation leading to preterm birth. J Clin Microbiol 2009, 47(1):38-47.

9. DiGiulio DB, Romero R, Amogan HP, Kusanovic JP, Bik EM, Gotsch F, Kim CJ, Erez O, Edwin S, Relman DA: Microbial prevalence, diversity and abundance in amniotic fluid during preterm labor: a molecular and culture-based investigation. PLoS One 2008, 3(8):e3056.

10. DiGiulio DB, Gervasi M, Romero R, Mazaki-Tovi S, Vaisbuch E, Kusanovic JP, Seok KS, Gomez R, Mittal P, Gotsch F, et al: Microbial invasion of the amniotic cavity in preeclampsia as assessed by cultivation and sequence-based methods. J Perinat Med 2010, 38(5):503-513.

11. Hanff PA, Rosol-Donoghue JA, Spiegel CA, Wilson KH, Moore LH: Leptotrichia sanguinegens sp. nov., a new agent of postpartum and neonatal bacteremia. Clin Infect Dis 1995, 20(Suppl 2):S237-239.

12. De Martino SJ, Mahoudeau I, Brettes JP, Piemont Y, Monteil H, Jaulhac B: Peripartum bacteremias due to Leptotrichia amnionii and Sneathia sanguinegens, rare causes of fever during and after delivery. I Clin Microbiol 2004, 42(12):5940-5943.

13. Bachy B, Bemer P, Tortellier L, Giraudeau C, Reynaud A, Corvec S: First case of septic arthritis due to Sneathia species most closely related to $S$. sanguinegens. J Med Microbiol 2011.

14. Koumans EH, Sternberg M, Bruce C, McQuillan G, Kendrick J, Sutton M, Markowitz LE: The prevalence of bacterial vaginosis in the United States, 2001-2004; associations with symptoms, sexual behaviors, and reproductive health. Sex Transm Dis 2007, 34(11):864-869.

15. Srinivasan S, Fredricks DN: The human vaginal bacterial biota and bacterial vaginosis. Interdiscip Perspect Infect Dis 2008, 2008:750479.

16. Fredricks DN, Fiedler TL, Thomas KK, Oakley BB, Marrazzo JM: Targeted PCR for detection of vaginal bacteria associated with bacterial vaginosis. J Clin Microbiol 2007, 45(10):3270-3276.

17. Haggerty $C L$, Totten PA, Ferris M, Martin DH, Hoferka S, Astete SG, Ondondo R, Norori J, Ness RB: Clinical characteristics of bacterial vaginosis among women testing positive for fastidious bacteria. Sex Transm Infect 2009, 85(4):242-248.

18. Ling Z, Kong J, Liu F, Zhu H, Chen X, Wang Y, Li L, Nelson KE, Xia Y, Xiang C: Molecular analysis of the diversity of vaginal microbiota associated with bacterial vaginosis. BMC Genomics 2010, 11:488.

19. Nelson DE, Van Der Pol B, Dong Q, Revanna KV, Fan B, Easwaran S, Sodergren E, Weinstock GM, Diao L, Fortenberry JD: Characteristic male urine microbiomes associate with asymptomatic sexually transmitted infection. PLoS One 2010, 5(11):e14116.

20. Nawrot R, Kamieniarz K, Malinowska M, Jozefiak A, Kedzia W, Kwasniewska A, Kuzma D, Gozdzicka-Jozefiak A: The prevalence of Leptotrichia amnionii in cervical swabs of HPV positive and negative women. Eur J Gynaecol Oncol 2010, 31(4):425-428.

21. Fettweis J, Alves J, Borzelleca J, Brooks J, Friedline C, Gao Y, Gao X, Girerd P, Harwich M, Hendricks S, et al: The Vaginal Microbiome: Disease, Genetics and the Environment. Nature Preceedings 2011 [http://dx.doi.org/10.1038/ npre.2011.5150.2].

22. Gaastra W, Boot R, Ho HT, Lipman LJ: Rat bite fever. Vet Microbiol 2009, 133(3):211-228.

23. Molina N, van Nimwegen E: Universal patterns of purifying selection at noncoding positions in bacteria. Genome Res 2008, 18(1):148-160.

24. Altschul SF, Madden TL, Schaffer AA, Zhang J, Zhang Z, Miller W, Lipman DJ: Gapped BLAST and PSI-BLAST: a new generation of protein database search programs. Nucleic Acids Res 1997, 25(17):3389-3402.

25. Bentley SD, Parkhill J: Comparative genomic structure of prokaryotes. Annu Rev Genet 2004, 38:771-792.

26. Rajan N, Cao Q, Anderson BE, Pruden DL, Sensibar J, Duncan JL, Schaeffer AJ: Roles of glycoproteins and oligosaccharides found in human vaginal fluid in bacterial adherence. Infect Immun 1999, 67(10):5027-5032.

27. Barabote RD, Saier MH Jr: Comparative genomic analyses of the bacterial phosphotransferase system. Microbiol Mol Biol Rev 2005, 69(4):608-634.

28. Alteri CJ, Smith SN, Mobley HL: Fitness of Escherichia coli during urinary tract infection requires gluconeogenesis and the TCA cycle. PLoS Pathog 2009, 5(5):e1000448.

29. Yu XJ, Walker DH, Liu Y, Zhang L: Amino acid biosynthesis deficiency in bacteria associated with human and animal hosts. Infect Genet Evol 2009, 9(4):514-517.

30. Gil R, Silva FJ, Pereto J, Moya A: Determination of the core of a minimal bacterial gene set. Microbiol Mol Biol Rev 2004, 68(3):518-537. 
31. Cao TB, Saier MH Jr: The general protein secretory pathway: phylogenetic analyses leading to evolutionary conclusions. Biochim Biophys Acta 2003, 1609(1):115-125

32. Dienes $L$ : The morphology of the $L 1$ of Klieneberger and its relationship to Streptobacillus moniliformis. J Bacteriol 1947, 54(2):231-237.

33. Harwich M, Alves J, Buck G, Strauss J, Patterson J, Oki A, Girerd P, Jefferson K: Drawing the line between commensal and pathogenic Gardnerella vaginalis through genome analysis and virulence studies. BMC Genomics 2010.

34. Arthi K, Appalaraju B, Parvathi S: Vancomycin sensitivity and $\mathrm{KOH}$ string test as an alternative to gram staining of bacteria. Indian J Med Microbiol 2003, 21(2):121-123.

35. Halebian S, Harris B, Finegold SM, Rolfe RD: Rapid method that aids in distinguishing Gram-positive from Gram-negative anaerobic bacteria. J Clin Microbiol 1981, 13(3):444-448.

36. Carey JC, Klebanoff MA, Hauth JC, Hillier SL, Thom EA, Ernest JM, Heine RP, Nugent RP, Fischer ML, Leveno K, et al: Metronidazole to prevent preterm delivery in pregnant women with asymptomatic bacterial vaginosis. National Institute of Child Health and Human Development Network of Maternal-Fetal Medicine Units. N Engl J Med 2000, 342(8):534-540.

37. Swidsinski A, Mendling W, Loening-Baucke $V$, Swidsinski S, Dorffel $Y$, Scholze J, Lochs H, Verstraelen H: An adherent Gardnerella vaginalis biofilm persists on the vaginal epithelium after standard therapy with oral metronidazole. Am J Obstet Gynecol 2008, 198(1):97, e91-96.

38. St Geme JW, Cutter D: The Haemophilus influenzae Hia adhesin is an autotransporter protein that remains uncleaved at the $C$ terminus and fully cell associated. J Bacteriol 2000, 182(21):6005-6013.

39. Tertti R, Skurnik M, Vartio T, Kuusela P: Adhesion protein YadA of Yersinia species mediates binding of bacteria to fibronectin. Infect Immun 1992, 60(7):3021-3024

40. Bukowski M, Rojowska A, Wladyka B: Prokaryotic toxin-antitoxin systemsthe role in bacterial physiology and application in molecular biology. Acta Biochim Pol 2011, 58(1):1-9.

41. Wang $X$, Wood TK: Toxin-antitoxin systems influence biofilm and persister cell formation and the general stress response. Appl Environ Microbiol 2011, 77(16):5577-5583.

42. Wiggins R, Hicks SJ, Soothill PW, Millar MR, Corfield AP: Mucinases and sialidases: their role in the pathogenesis of sexually transmitted infections in the female genital tract. Sex Transm Infect 2001, 77(6):402-408.

43. Lecuit M, Nelson DM, Smith SD, Khun H, Huerre M, Vacher-Lavenu MC, Gordon Jl, Cossart P: Targeting and crossing of the human maternofetal barrier by Listeria monocytogenes: role of internalin interaction with trophoblast E-cadherin. Proc Natl Acad Sci USA 2004, 101(16):6152-6157.

44. Karginov FV, Hannon GJ: The CRISPR system: small RNA-guided defense in bacteria and archaea. Mol Cell 2010, 37(1):7-19.

45. Grissa I, Vergnaud G, Pourcel C: CRISPRFinder: a web tool to identify clustered regularly interspaced short palindromic repeats. Nucleic Acids Res 2007, 35 Web Server: W52-57.

46. Wilson KH, Blitchington RB, Greene RC: Amplification of bacterial $16 \mathrm{~S}$ ribosomal DNA with polymerase chain reaction. J Clin Microbio/ 1990, 28(9):1942-1946.

47. Geshnizgani $A M$, Onderdonk AB: Defined medium simulating genital tract secretions for growth of vaginal microflora. J Clin Microbiol 1992, 30(5):1323-1326.

48. Salzberg SL, Pertea M, Delcher AL, Gardner MJ, Tettelin H: Interpolated Markov models for eukaryotic gene finding. Genomics 1999, 59(1):24-31

49. Lowe TM, Eddy SR: tRNAscan-SE: a program for improved detection of transfer RNA genes in genomic sequence. Nucleic Acids Res 1997, 25(5):955-964

50. Alves JM, Buck GA: Automated system for gene annotation and metabolic pathway reconstruction using general sequence databases. Chem Biodivers 2007, 4(11):2593-2602.

51. Suzek BE, Huang H, McGarvey P, Mazumder R, Wu CH: UniRef: comprehensive and non-redundant UniProt reference clusters. Bioinformatics 2007, 23(10):1282-1288.

52. Krogh A, Larsson B, von Heijne G, Sonnhammer EL: Predicting transmembrane protein topology with a hidden Markov model: application to complete genomes. J Mol Biol 2001, 305(3):567-580.
53. Bendtsen JD, Nielsen H, von Heijne G, Brunak S: Improved prediction of signal peptides: SignalP 3.0. J Mol Biol 2004, 340(4):783-795.

54. Thompson JD, Higgins DG, Gibson TJ: CLUSTAL W: improving the sensitivity of progressive multiple sequence alignment through sequence weighting, position-specific gap penalties and weight matrix choice. Nucleic Acids Res 1994, 22(22):4673-4680

55. Stamatakis A, Ott M: Efficient computation of the phylogenetic likelihood function on multi-gene alignments and multi-core architectures. Philos Trans R Soc Lond B Biol Sci 2008, 363(1512):3977-3984.

56. Guindon S, Gascuel O: A simple, fast, and accurate algorithm to estimate large phylogenies by maximum likelihood. Syst Biol 2003, 52(5):696-704.

57. Guindon S, Dufayard JF, Lefort V, Anisimova M, Hordijk W, Gascuel O: New algorithms and methods to estimate maximum-likelihood phylogenies: assessing the performance of PhyML 3.0. Syst Biol 2010, 59(3):307-321.

58. Carver T, Thomson N, Bleasby A, Berriman M, Parkhill J: DNAPlotter: circular and linear interactive genome visualization. Bioinformatics 2009, 25(1):119-120.

doi:10.1186/1471-2164-13-S8-S4

Cite this article as: Harwich et al:: Genomic sequence analysis and characterization of Sneathia amnii sp. nov. BMC Genomics 2012 13(Suppl 8):S4.

\section{Submit your next manuscript to BioMed Central and take full advantage of:}

- Convenient online submission

- Thorough peer review

- No space constraints or color figure charges

- Immediate publication on acceptance

- Inclusion in PubMed, CAS, Scopus and Google Scholar

- Research which is freely available for redistribution

Submit your manuscript at www.biomedcentral.com/submit
Biomed Central 